\title{
ANALISIS DAERAH PENANGKAPAN IKAN PADA MASA PERALIHAN I DAN II MENGGUNAKAN DATA ALTIMETRI (Studi Kasus: Selat Bali)
}

\author{
Yuwono', Firdaus Amirullah Su'udi² \\ ${ }^{1,2}$ Departemen Geomatika, FTSLK-ITS Sukolilo, Surabaya 60111, Indonesia \\ e-mail: yuwono@geodesy.its.ac.id
}

\begin{abstract}
Abstrak
Potensi perikanan di Indonesia sangat besar karena hal ini didukung oleh wilayah Indonesia yang hampir dua pertiganya berupa laut. Salah satu wilayah yang kaya akan perikanannya adalah di Selat Bali. Oleh karena itu, diperlukan metode yang dapat digunakan sebagai acuan untuk mengidentifikasi persebaran dan Daerah Penangkapan Ikan (ZPPI). Salah satu metode yang dapat digunakan adalah metode pemodelan numerikal menggunakan data altimetri yaitu data arus geostropik dan data tinggi muka laut absolut yang ditumpang susun sehingga identifikasi daerah penangkapan ikan dapat dilakukan. Selain itu juga diperlukan data tambahan dari parameter oseanografi lainnya untuk meningkatkan keakuratan Daerah Penangkapan Ikan di wilayah Selat Bali. Dari hasil penelitian didapatkan kecepatan arus geostropik Tanggal 11 April 2012 memiliki kecepatan minimum 0,001 m/s dan kecepatan maksimum 1,122 m/s sedangkan Kecepatan arus geostropik Tanggal 09 Oktober 2012 memiliki kecepatan minimum 0,004 m/s dan kecepatan maksimum 0,670 m/s. Tinggi muka laut pada Tanggal 11 April 2012 minimum 0,852 m dan maksimum 1,094 m sedangkan tinggi muka laut pada Tanggal 09 Oktober 2012 minimum 0,737 m dan maksimum 0,840 m. Anomali tinggi muka laut pada Tanggal 11 April 2012 mempunyai nilai tinggi minimum $-0,082 \mathrm{~m}$ dan tinggi maksimum 0,160 m, sedangkan anomali tinggi muka laut pada Tanggal 09 Oktober 2012 nilai tinggi minimum -0,038 $\mathrm{m}$ dan tinggi maksimum 0,065 $\mathrm{m}$. Korelasi antara Kecepatan arus geosptropik dan anomali tinggi muka laut pada Tanggal 11 April 2012 mempunyai nilai sebesar 0,664 m, sedangkan pada Tanggal 09 Oktober 2012 mempunyai nilai 0,697 m.Terdapat pergeseran antara Daerah Penangkapan ikan pada masa peralihan I dan II. Hal ini dikarenakan tinggi muka laut yang semakin menurun dari bulan April hingga Oktober 2012. Oleh karena itu, diperlukan survei primer ke Selat Bali untuk mendapatkan validasi data jenis ikan yang berada di Zona yang dianggap sebagai ZPPI.
\end{abstract}

Kata Kunci: Perikanan, Daerah Penangkapan Ikan, Selat Bali, Arus Geostropik, tinggi muka laut absolut

\section{PENDAHULUAN}

Negara Indonesia memiliki luas wilayah hampir dua pertiganya berupa laut, oleh karena itu sering disebut sebagai negara maritim. Sebagai negara maritim, Indonesia memiliki keunggulan komparatif dalam potensi sumberdaya perikanan dan kelautan. Menurut hasil evaluasi berdasarkan data dan informasi yang ada sampai saat ini secara keseluruhan menunjukkan perkiraan potensi lestari sumberdaya perikanan laut sebesar 6,6 juta ton/tahun dengan perkiraan sebesar 4,5 juta ton/tahun terdapat di perairan teritorial dan 2,1 juta ton per tahun terdapat di perairan ZEE Indonesia (Zona Ekonoi Eksklusif) [4].

Selat Bali merupakan selat yang terletak diantara Pulau Jawa dan Pulau Bali. Selat ini merupakan daerah yang potensial dengan tangkapan ikannya dikarenakan faktor letaknya yang dipengaruhi oleh Laut Jawa dan Samudera Hindia. Hal ini menyebabkan perairan Selat Bali terdapat banyak nutrien sumber makanan untuk ikan [2].

Oleh karena itu diperlukan beberapa metode Penentuan Daerah Penangkapan Ikan (ZPPI) sebagai upaya untuk mengidentifikasi dan menganalisis lokasi-lokasi yang berpotensi sebagai ZPPI. Metode yang dapat digunakan yaitu dengan menggunakan metode penginderaan jauh dan pemodelan numerik [5].

Satelit altimetri adalah satelit yang berfungsi untuk memantau topografi dan dinamika yang terjadi di permukaan laut. Satelit altimetri dapat digunakan untuk pengamatan mengenai perubahan arus permukaan secara global. Dengan beroperasinya beberapa satelit altimetri dapat diperoleh data yang diperlukan untuk kegiatan penelitian terkait dinamika laut seperti permukaan laut, arus geostropik, angin di 
permukaan laut dan gelombang laut. Dengan ketersediaan data dan terkait dengan pemanfaatannya, satelit altimetri dapat digunakan untuk mengkaji tentang analisis ZPPI. Analisis ZPPI tersebut dapat didentifikasi dengan menggunakan data arus geostropik permukaan laut dan data tinggi muka laut absolut sebagai data pendukung dari satelit altimetri. Arus geostropik adalah arus yang terjadi di permukaan laut akibat pengaruh gaya gradien tekanan mendatar dan diseimbangkan oleh gaya coriolis sedangkan tinggi muka laut absolut merupakan tinggi permukaan laut yang diperoleh dari peratarataan topografi dinamik ditambah anomali tinggi muka air laut terhadap perata-rataan tinggi muka air laut dalam selang waktu tertentu. Arus geostropik dapat mendeteksi dan memahami fenomena yang terjadi di perairan seperti: arus eddy, upwelling dan downwelling [3].

Dalam penelitian ini digunakan data-data dari satelit altimetri gabungan (HY-2A, Saral/AltiKa, Cryosat-2, dan Jason-2) dengan studi kasus di Selat Bali. Waktu yang digunakan yaitu pada tanggal 11 April 2012 sebagai sampel dari masa peralihan I dan tanggal 09 Oktober 2012 sebagai sampel dari masa peralihan II. Hal ini merujuk pada hasil dari penelitian sebelumnya bahwa pada saat masa Peralihan I dan Peralihan II, Selat Bali merupakan wilayah yang selalu subur akan sumber makanan yang dibutuhkan oleh ikan [6]. Pengolahan data satelit altimetri gabungan ini dilakukan untuk memperoleh informasi topografi tinggi muka laut absolut dan arah arus geostropik. Informasi tersebut kemudian digunakan untuk menentukan ZPPI yang berada pada Selat Bali.

Setelah penelitian ini, hasilnya diharapkan dapat membantu para peneliti untuk mengidentifikasi ZPPI secara akurat. Selain itu, diharapkan dengan memperoleh data yang valid bisa digunakan oleh para nelayan Indonesia dan khususnya oleh nelayan di sekitar Selat Bali.

Berikut akan dibahas tentang bagaimana cara mengolah data Tinggi Muka Laut Absolut dan anomalinya serta pergerakan Arus Geostropik pada data altimetry, menggunakan data satelit altimetry, dan memvalidasi Daerah Penangkapan
Ikan pada hasil Penelitian menggunakan data satelit altimetry.

Sebagai batasan yang digunakan adalah objek yang digunakan yaitu tinggi muka laut absolut dan pergerakan arus geostropik di wilayah Indonesia

Penelitian bertujuan untuk melakukan proses pengolahan data tinggi muka laut absolut dan anomalinya pada masa peralihan I dan II, melakukan proses pengolahan data arus geostropik laut, mengetahui korelasi antara arus geostropik dan anomali tinggi muka laut absolut, serta melakukan analisis terkait ZPPI dan data In Situ di wilayah Selat Bali.

\section{METODOLOGI PENELITIAN}

\section{Lokasi Penelitian}

Lokasi penelitian ini yaitu perairan Selat Bali. Wilayah penelitian ini berada pada koordinat $7^{\circ}$ 24' 6,64" LS - 9० 25' 46,66" LS dan $113^{\circ} 53^{\prime} 39,92^{\prime \prime}$ BT- $115^{\circ} 17^{\prime} 4,72^{\prime \prime}$ BT. Lokasi penelitian dapat dilihat pada gambar 1 sebagai berikut:
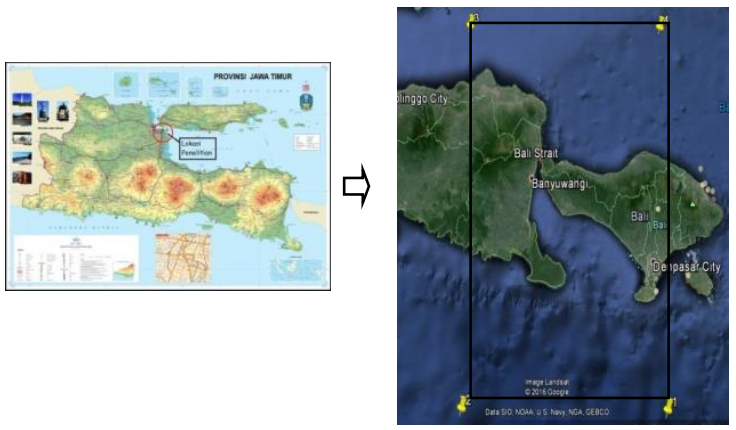

Gambar 1. Lokasi Penelitian

\section{Data Dan Peralatan}

Data yang digunakan dalam penelitian ini adalah: Data arus geostropik dan Absolute Dynamic Topography Satelit altimetri gabungan (HY-2A, Saral/AltiKa, Cryosat-2, dan Jason-2) pada tanggal 11 April 2012 dan 09 Oktober 2012.

Data tambahan berupa data in situ salinitas, klorofil-a, dan suhu permukaan laut di Selat Bali

\section{Peralatan}

Peralatan yang digunakan dalam penelitian ini adalah:

a. Software pembuatan vektor arus geostropik dan kontur anomali tinggi muka laut 
b. Software untuk eksport data arus geostropik dan tinggi muka laut

Pengolahan data dilakukan dengan urutn seperti terlihat pada Gambar 2.

\section{Diagram Alir Pengolahan Data}

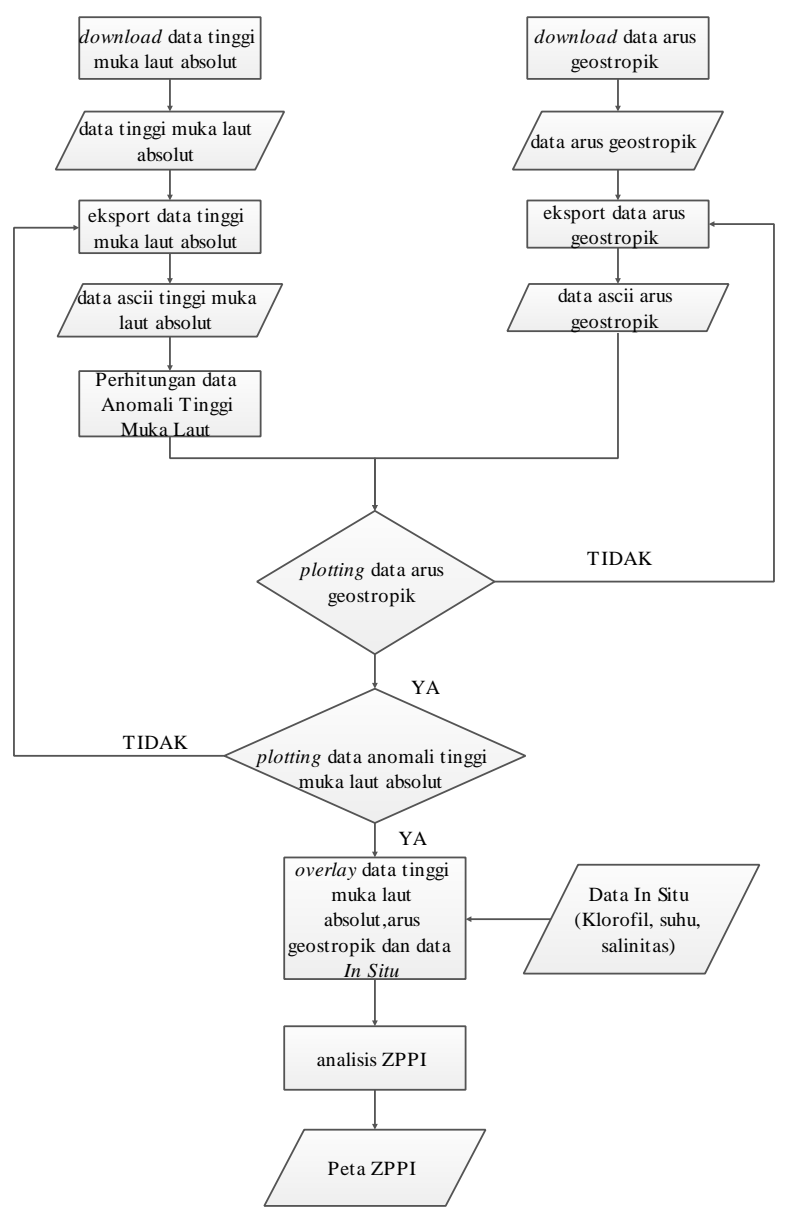

Gambar 2. Diagram Tahap Pengolahan Data

\section{HASIL DAN PEMBAHASAN}

\section{Hasil Plotting Arus Geostropik Absolut}

Gambar 3 dan Gambar 4 secara berurutan menunjukkan kecepatan arus geostropik pada Tanggal 11 April 2012 dan Tanggal 09 Oktober 2012 di Selat Bali. Kecepatan arus geostropik Tanggal 11 April 2012 memiliki kecepatan minimum $0,001 \mathrm{~m} / \mathrm{s}$ dan kecepatan maksimum $1,122 \mathrm{~m} / \mathrm{s}$ sedangkan Kecepatan arus geostropik Tanggal 09 Oktober 2012 memiliki kecepatan minimum $0,004 \mathrm{~m} / \mathrm{s}$ dan kecepatan maksimum $0,670 \mathrm{~m} / \mathrm{s}$.
Pada Gambar 3 dan Gambar 4, arah pergerakan arus geostropik terlihat berputar searah jarum jam (siklonik) hingga membentuk pusaran yang ditandai oleh lingkaran merah dan berputar secara anti-siklonik (berlawanan arah jarum jam) yang ditandai oleh lingkaran biru. Pada arus eddy yang berputar siklonik di selat bali terbentuk kejadian upwelling dan arus eddy yang berputar secara anti-siklonik terbentuk kejadian downwelling. Hal ini diakibatkan oleh wilayah selat bali yang berada di selatan ekuator (stewart 2008).

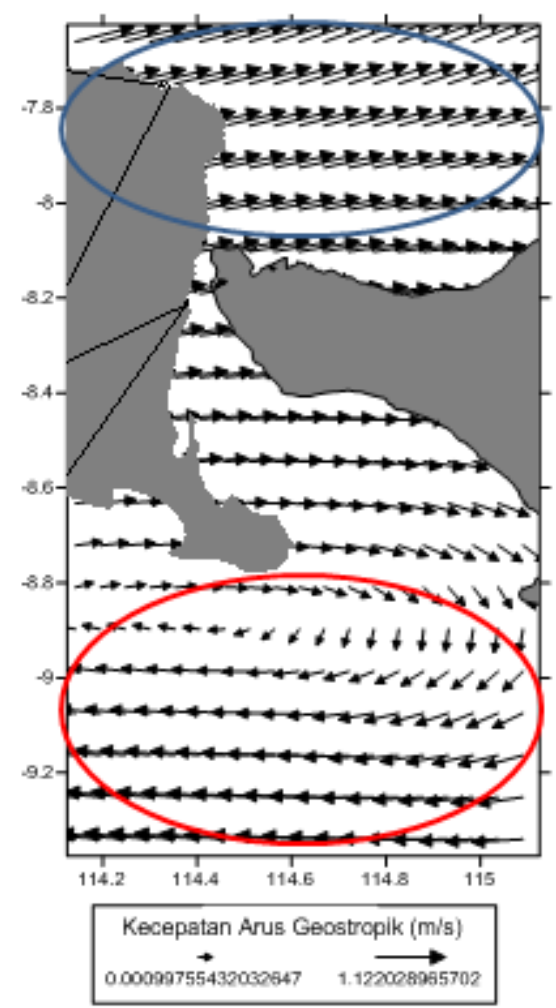

Gambar 3. Vektor pergerakan arus geostropik Tanggal 11 April 2012 


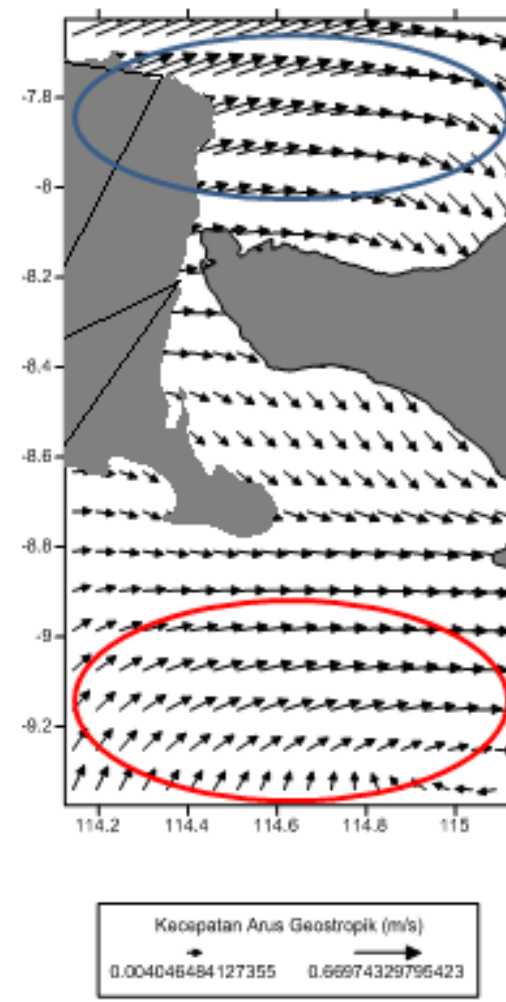

Gambar 4. Vektor pergerakan arus geostropik Tanggal 09 Oktober 2012

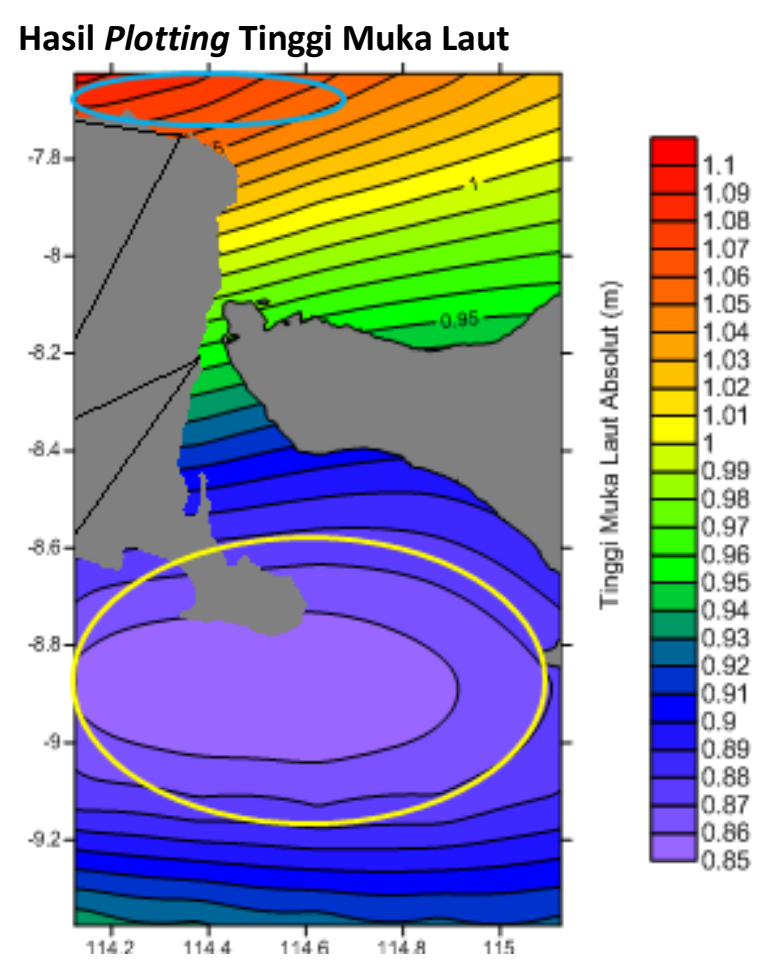

Gambar 5. Kontur Tinggi Muka Laut di Selat Bali Tanggal 11 April 2012

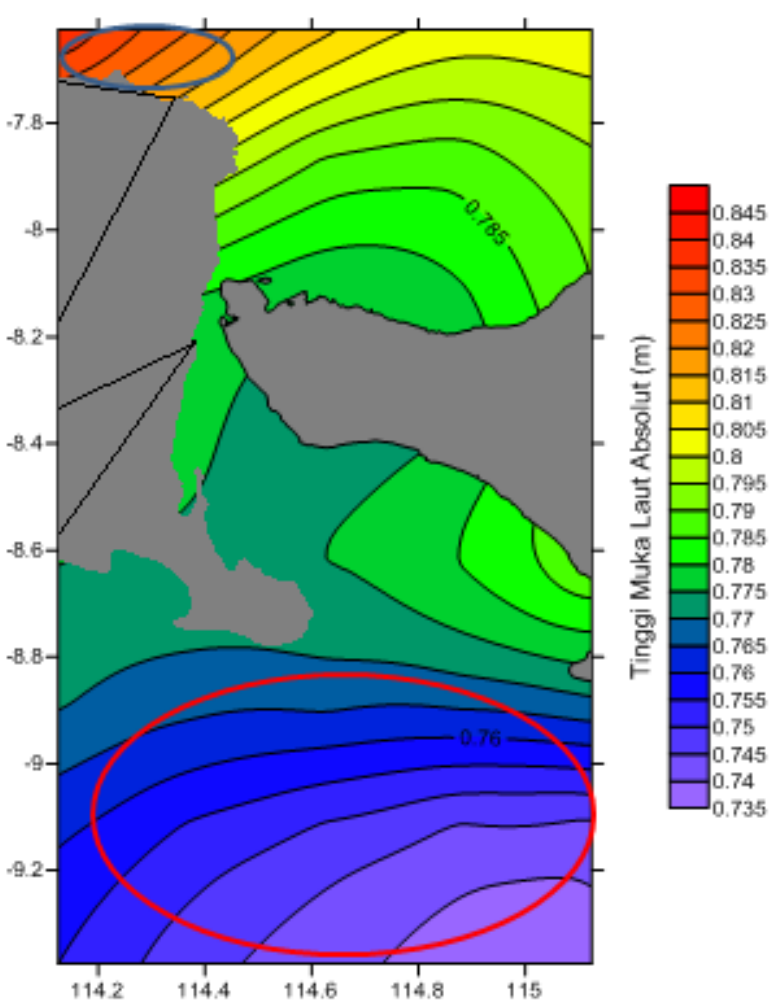

Gambar 6. Kontur Tinggi Muka Laut di Selat Bali Tanggal 09 Oktober 2012

Gambar 5 dan Gambar 6 secara berurutan menunjukkan pola tinggi muka laut pada Tanggal 11 April 2012 dan Tanggal 09 Oktober 2012. Tinggi muka laut pada Tanggal 11 April 2012 mempunyai nilai tinggi minimum $0,852 \mathrm{~m}$ dan tinggi maksimum 1,094 $\mathrm{m}$ sedangkan tinggi muka laut pada Tanggal 09 Oktober 2012 mempunyai nilai tinggi minimum $0,737 \mathrm{~m}$ dan tinggi maksimum $0,845 \mathrm{~m}$.

Pada gambar 5 dan gambar 6 terlihat bahwa di Selat Bali terjadi fenomena upwelling. Hal ini ditandai dengan ketinggian permukaan laut yang lebih rendah dari sekitarnya seperti yang ditunjukkan oleh lingkaran merah. Fenomena upwelling tersebut terjadi akibat dari arus eddy siklonik yang berasosiasi dengan tinggi muka laut yang rendah.

Selain itu juga pada gambar 5 dan gambar 6 telah terjadi fenomena downwelling yang ditandai dengan ketinggian permukaan laut yang lebih tinggi dari sekitarnya seperti yang ditunjukkan oleh lingkaran biru. Fenomena downwelling tersebut terjadi akibat dari arus eddy anti-siklonik 
yang berasosiasi dengan tinggi muka laut yang tinggi.

\section{Anomali Tinggi Muka Laut}

Anomali tinggi muka laut Selat Bali didapatkan dengan perhitungan selisih antara tinggi muka laut sesaat pada tiap titik pengamatan terhadap hasil rata-rata tinggi muka laut. Hasil anomali tinggi muka laut yang telah didapatkan sebagai berikut:

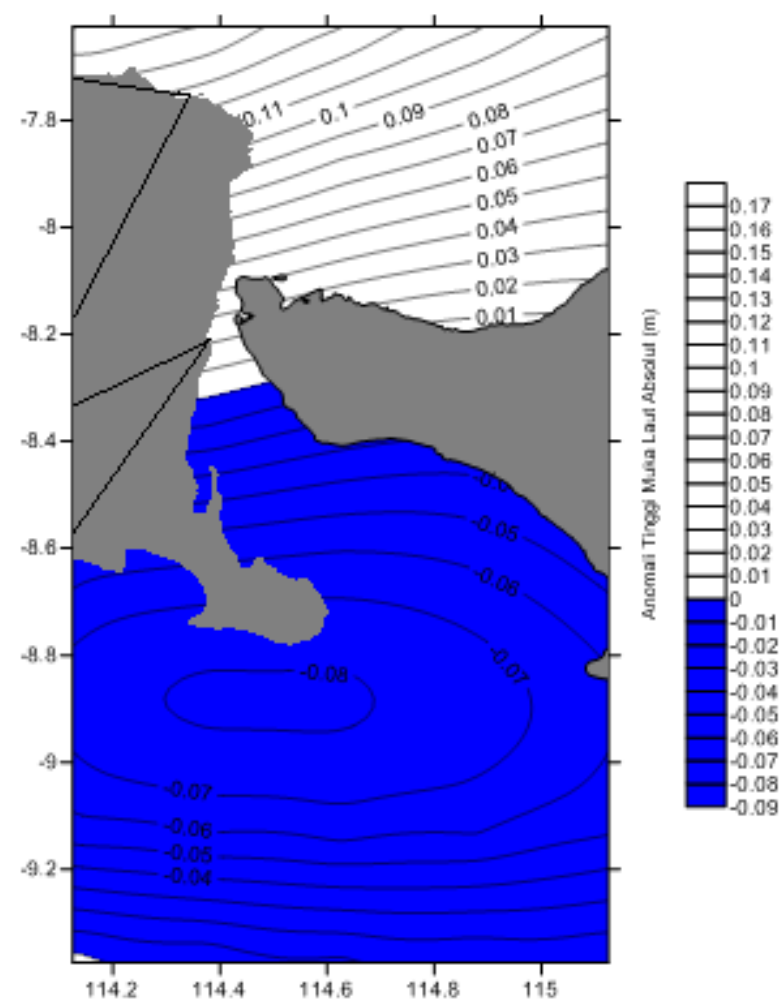

Gambar 7. Anomali positif (putih) dan Anomali Negatif (biru) di Selat Bali Tanggal 11 April 2012

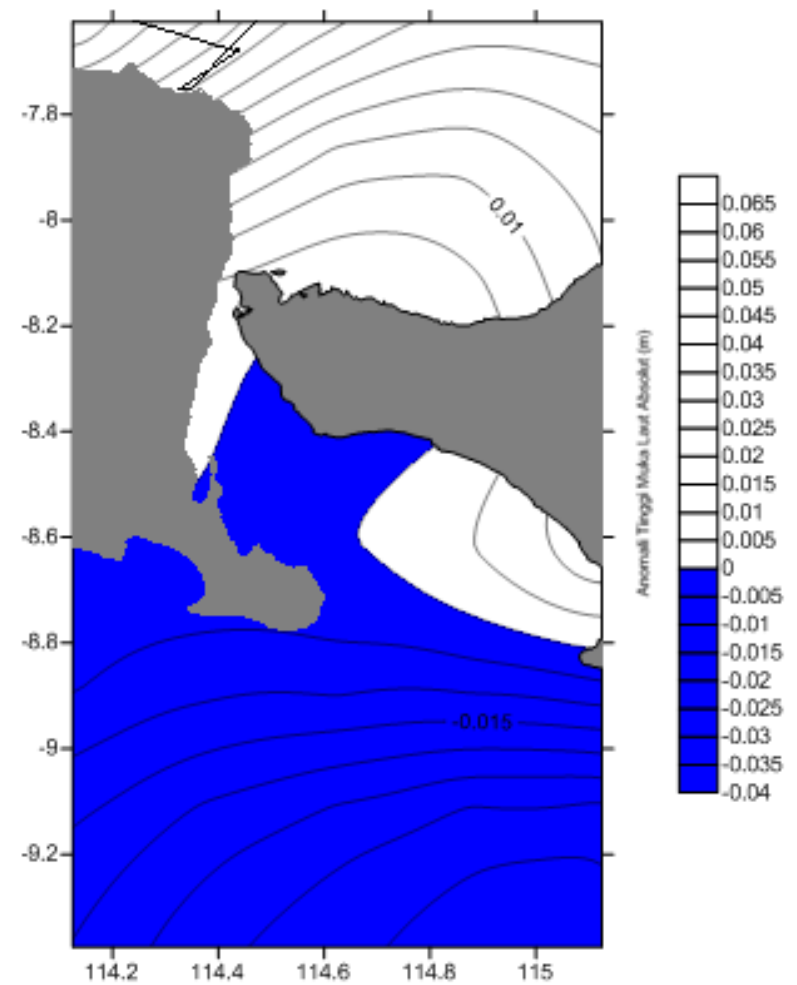

Gambar 8. Anomali positif (putih) dan Anomali Negatif (biru) di Selat Bali Tanggal 09 Oktober 2012

Gambar 7 dan Gambar 8 secara berurutan menunjukkan anomali tinggi muka laut pada Tanggal 11 April 2012 dan 09 Oktober 2012. Anomali tinggi muka laut pada Tanggal 11 April 2012 mempunyai nilai tinggi minimum $-0,082 \mathrm{~m}$ dan tinggi maksimum 0,160 m sedangkan Anomali tinggi muka laut pada Tanggal 09 Oktober 2012 mempunyai nilai tinggi minimum $-0,038 \mathrm{~m}$ dan tinggi maksimum $0,065 \mathrm{~m}$. Anomali tinggi muka laut tersebut diasosiasikan dengan pertemuan arus eddy yang berbeda arah untuk mengidentifikasi Daerah Penangkapan Ikan di daerah Selat Bali. 
Hasil Overlay Data dan Analisis Data

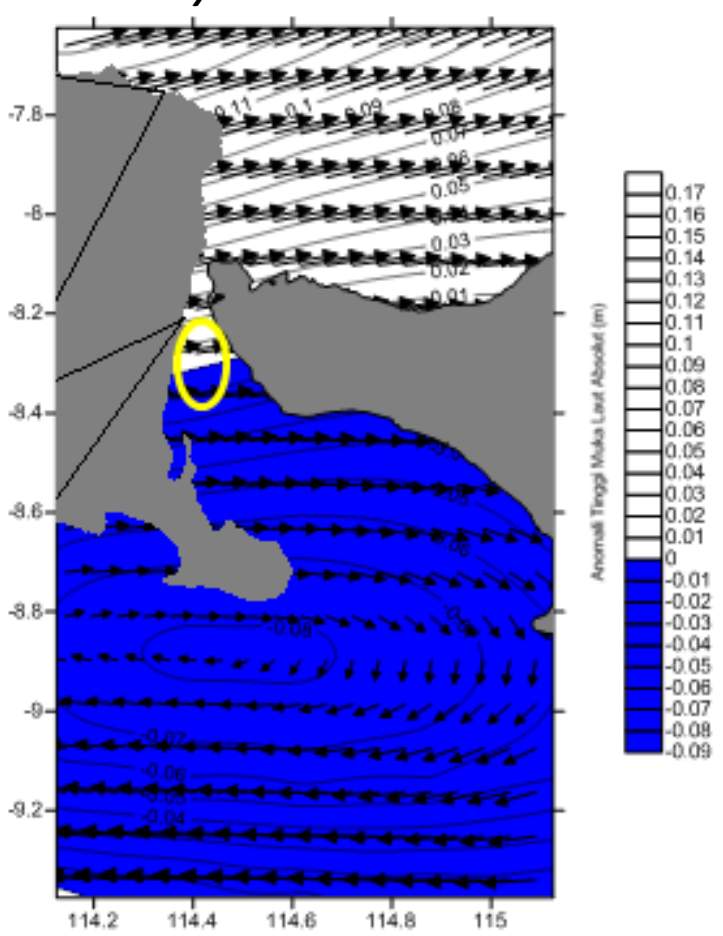

Gambar 9. Overlay data di Selat Bali Tanggal 11 April 2012

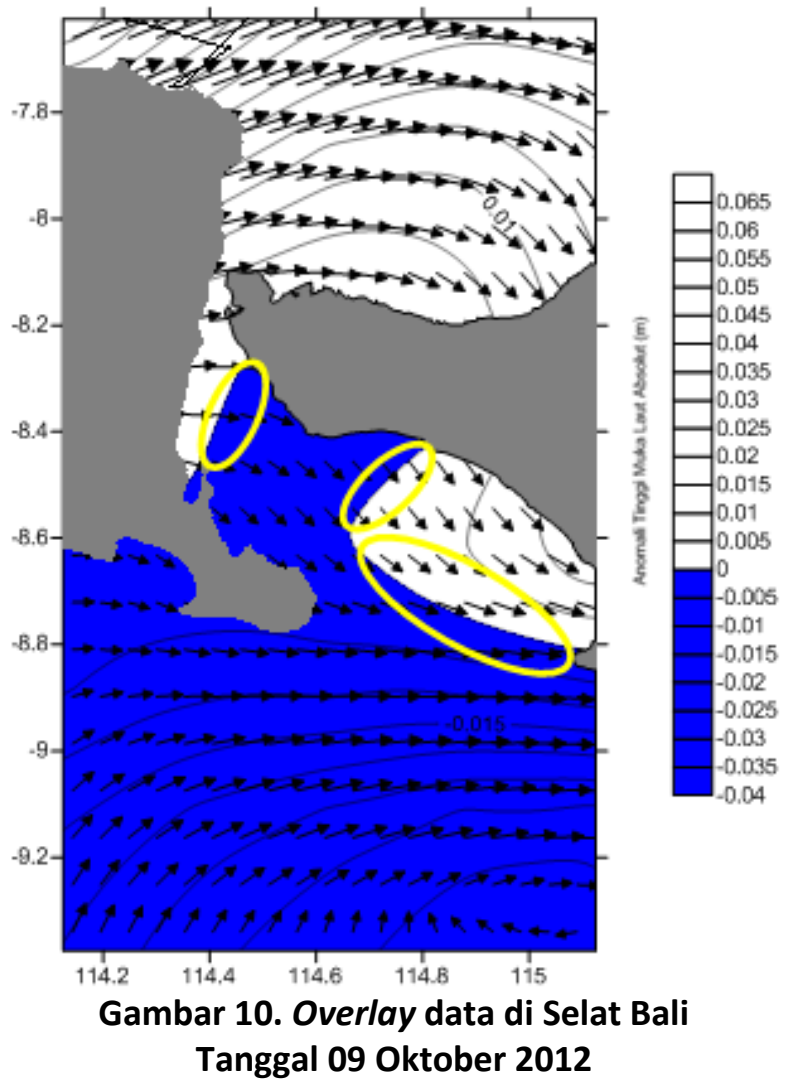

Dari hasil overlay data arus geostropik dan Anomali Tinggi Muka Laut didapatkan bahwa daerah upwelling memiliki kecepatan arus yang kecil dibandingkan dengan daerah downwelling. Hal ini ditandai dengan nilai simbol panah pada masing-masing daerah.

Penentuan Daerah Penangkapan Ikan pada penelitian ini dilakukan dengan mengidentifikasi Zona pertemuan antara dua arus eddy yang berbeda arah dan berasosiasi dengan pertemuan anomali tinggi permukaan laut yang positif dan negatif. Zona tersebut merupakan zona yang berpotensi sebagai daerah penangkapan ikan (McGillicuddy et al 1998 dalam Marpaung dan Prayogo 2014). Bulatan kuning pada gambar 9 dan gambar 10 menunjukkan daerah pertemuan antara dua arus eddy yang berlawan arah yang berasosiasi dengan anomali tinggi muka laut. Daerah tersebut dapat diindentifikasi sebagai Daerah Penangkapan Ikan. Pada gambar tersebut juga terdapat pergeseran antara Daerah Penangkapan ikan pada Tanggal 11 April 2012 dan 09 Oktober 2012. Hal ini bisa disebabkan karena tinggi muka laut yang semakin menurun dari bulan April 2012 hingga bulan Oktober 2012.ZPPI yang dihasilkan masih bersifat umum dan perlu dilakukan validasi dengan menambahkan parameter oseanografi lain untuk penentuan ikan agar lebih akurat.

Korelasi Arus Geostropik dan Anomali Tinggi Muka Laut

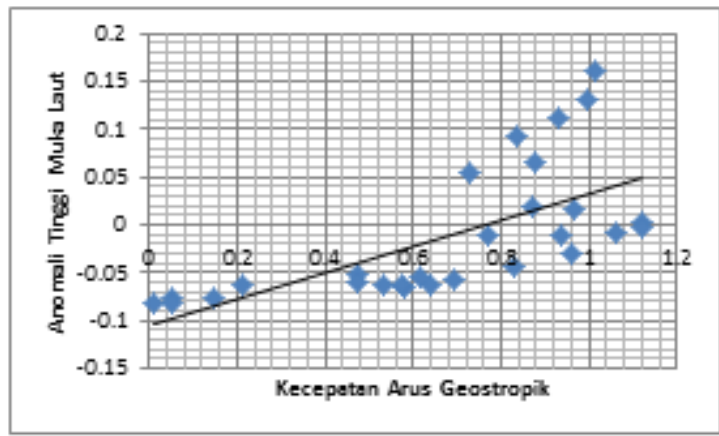

Gambar 11. Analisis Korelasi Kecepatan Arus Geostropik dan Anomali Tinggi muka Laut di Selat Bali Tanggal 11 April 2012 


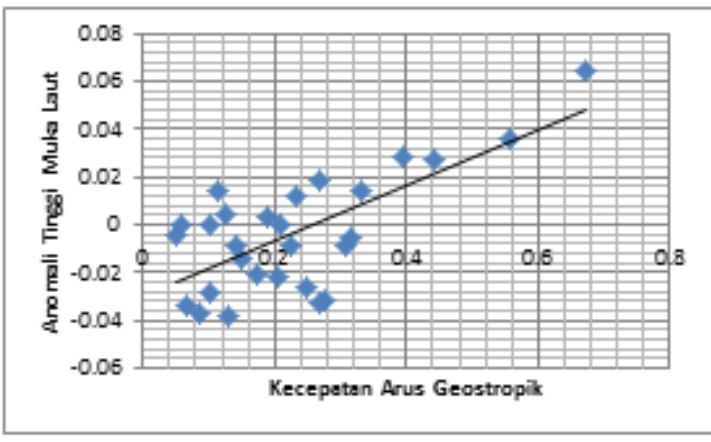

Gambar 12. Analisis Korelasi Kecepatan Arus Geostropik dan Anomali Tinggi muka Laut di Selat Bali Tanggal 09 Oktober 2012

Dari hasil perhitungan dan analisis korelasi menggunakan rumus korelasi pearson didapatkan bahwa korelasi antara arus geostropik dan anomali tinggi muka laut pada Tanggal 11 April 2012 mempunyai korelasi positif dan bernilai sebesar 0,66, sedangkan pada Tanggal 09 Oktober 2012 juga mempunyai korelasi positif dan benilai 0,70 . hal ini menunjukkan bahwa hubungan antara arus geostropik dan anomali tinggi muka laut memiliki korelasi kuat.

\section{Analisis Overlay dengan Data In Situ}

Dalam penelitian ini digunakan data tambahan titik sampel pengukuran salinitas, klorofil-a, dan suhu permukaan laut dari data In Situ pada Tanggal 11 April 2012 dan 09 Oktober 2012 yang diperoleh dari Balai Penelitian dan Observasi Laut (BPOL) sebagai data pendukung Daerah Penangkapan Ikan yang lebih akurat. Data tersebut ditumpang susun terhadap data arus geostropik dan anomali tinggi muka laut dari data altimetri. Data In Situ yang diperoleh sebagai berikut:

Tabel 1. Data In Situ Tanggal 11 April 2012

\begin{tabular}{cccccc}
\hline Titik & Lintang & Bujur & $\begin{array}{c}\text { salinitas } \\
(\mathrm{psu})\end{array}$ & $\begin{array}{c}\text { suhu } \\
\left({ }^{\circ} \mathrm{C}\right)\end{array}$ & $\begin{array}{c}\text { Klorofil } \\
(\mathrm{mg} / \mathrm{m} 3)\end{array}$ \\
\hline 1 & $-8^{\circ} 24^{\prime} 22,46^{\prime \prime}$ & $114^{\circ} 32^{\prime} 49,4^{\prime \prime}$ & 31,60 & 28,30 & 0,14 \\
2 & $-8^{\circ} 26^{\prime} 18,06^{\prime \prime}$ & $114^{\circ} 32^{\prime} 45,8^{\prime \prime}$ & 31,60 & 28,60 & 0,38 \\
3 & $-8^{\circ} 28^{\prime} 22,37^{\prime \prime}$ & $114^{\circ} 32^{\prime} 45,4^{\prime \prime}$ & 24,70 & 28,70 & 0,15 \\
4 & $-8^{\circ} 27^{\prime} 11,02^{\prime \prime}$ & $114^{\circ} 35^{\prime} 10,6^{\prime \prime}$ & 31,60 & 28,80 & 0,23 \\
5 & $-8^{\circ} 25^{\prime} 45,12^{\prime \prime}$ & $114^{\circ} 37^{\prime} 30,5^{\prime \prime}$ & 31,50 & 28,50 & 0,29 \\
6 & $-8^{\circ} 28^{\prime} 18,23^{\prime \prime}$ & $114^{\circ} 37^{\prime} 9,26^{\prime \prime}$ & 31,80 & 28,90 & 0,29 \\
7 & $-8^{\circ} 30^{\prime} 39,71^{\prime \prime}$ & $114^{\circ} 36^{\prime} 45,1^{\prime \prime}$ & 31,20 & 28,60 & 0,18 \\
8 & $-8^{\circ} 28^{\prime} 47,89^{\prime \prime}$ & $114^{\circ} 39^{\prime} 13,9^{\prime \prime}$ & 31,60 & 28,60 & 0,19 \\
\hline
\end{tabular}

Tabel 2. Data In Situ Tanggal 09 Oktober 2012

\begin{tabular}{cccccc}
\hline Titik & Lintang & Bujur & $\begin{array}{c}\text { salinitas } \\
\text { (psu) }\end{array}$ & $\begin{array}{c}\text { suhu } \\
\left({ }^{\circ} \mathrm{C}\right)\end{array}$ & $\begin{array}{c}\text { Klorofil } \\
\left(\mathrm{mg}^{\prime} \mathrm{m}^{\prime}\right)\end{array}$ \\
\hline 1 & $-8^{\circ} 24^{\prime} 22,46^{\prime \prime}$ & $114^{\circ} 32^{\prime} 49,4^{\prime \prime}$ & 34,30 & 26,83 & 0,27 \\
2 & $-8^{\circ} 26^{\prime} 18,06^{\prime \prime}$ & $114^{\circ} 32^{\prime} 45,8^{\prime \prime}$ & 34,60 & 27,67 & 0,10 \\
3 & $-8^{\circ} 28^{\prime} 22,37^{\prime \prime}$ & $114^{\circ} 32^{\prime} 45,4^{\prime \prime}$ & 34,60 & 28,03 & 0,20 \\
4 & $-8^{\circ} 27^{\prime} 11,02^{\prime \prime}$ & $114^{\circ} 35^{\prime} 10,6^{\prime \prime}$ & 34,40 & 27,27 & 0,53 \\
5 & $-8^{\circ} 25^{\prime} 45,12^{\prime \prime}$ & $114^{\circ} 37^{\prime} 30,5^{\prime \prime}$ & 34,17 & 28,03 & 0,31 \\
6 & $-8^{\circ} 28^{\prime} 18,23^{\prime \prime}$ & $114^{\circ} 37^{\prime} 9,26^{\prime \prime}$ & 34,53 & 27,37 & 0,46 \\
7 & $-8^{\circ} 30^{\prime} 39,71^{\prime \prime}$ & $114^{\circ} 36^{\prime} 45,1^{\prime \prime}$ & 34,50 & 27,53 & 0,10 \\
8 & $-8^{\circ} 28^{\prime} 47,89^{\prime \prime}$ & $114^{\circ} 39^{\prime} 13,9^{\prime \prime}$ & 34,40 & 27,20 & 0,10 \\
9 & $-8^{\circ} 27^{\prime} 4,61^{\prime \prime}$ & $114^{\circ} 41^{\prime} 31^{\prime \prime}$ & 34,33 & 26,80 & 0,15 \\
10 & $-8^{\circ} 25^{\prime} 32,77^{\prime \prime}$ & $114^{\circ} 43^{\prime} 24,8^{\prime \prime}$ & 33,90 & 27,20 & 0,19 \\
11 & $-8^{\circ} 28^{\prime} 8,62^{\prime \prime}$ & $114^{\circ} 42^{\prime} 34,5^{\prime \prime}$ & 34,30 & 26,60 & 0,20 \\
\hline
\end{tabular}

Dari data-data In Situ tersebut, dipilih nilai-nilai parameter klorofil, Suhu, dan Salinitas yang sesuai dengan jenis Ikan. Karakteristik beberapa jenis ikan. Untuk parameter klorofil-a, daerah yang berpotensi Ikan mempunyai nilai Klorofil-a berkisar 0,2-0,5 mg/m (Insanu, Handayani, dan Sukojo 2013).

Prediksi karakteristik ikan yang memenuhi nilai parameter suhu dan salinitas data In Situ tanggal 11 April 2012 tersebut yaitu ikan Kakap Merah yang memiliki salinitas sebesar 30-33 ppt serta suhu antara 5-32ㅇ $C$ yang berada pada titik 2, 4, 5, 6. Karakteristik ikan yang memenuhi nilai parameter suhu dan salinitas data In Situ tanggal 09 Oktober 2012 tersebut yaitu ikan Tuna dan Cakalang yang memiliki suhu $17^{\circ}-31^{\circ} \mathrm{C}$ dan Salinitas perairan yang disukai berkisar $32-35 \mathrm{ppt}$ yang berada pada titik 1, 3, 4, 5, 6, 11 .

Hasil overlay data arus geostropik dan anomali tinggi muka laut dengan data In Situ sebagai berikut: 


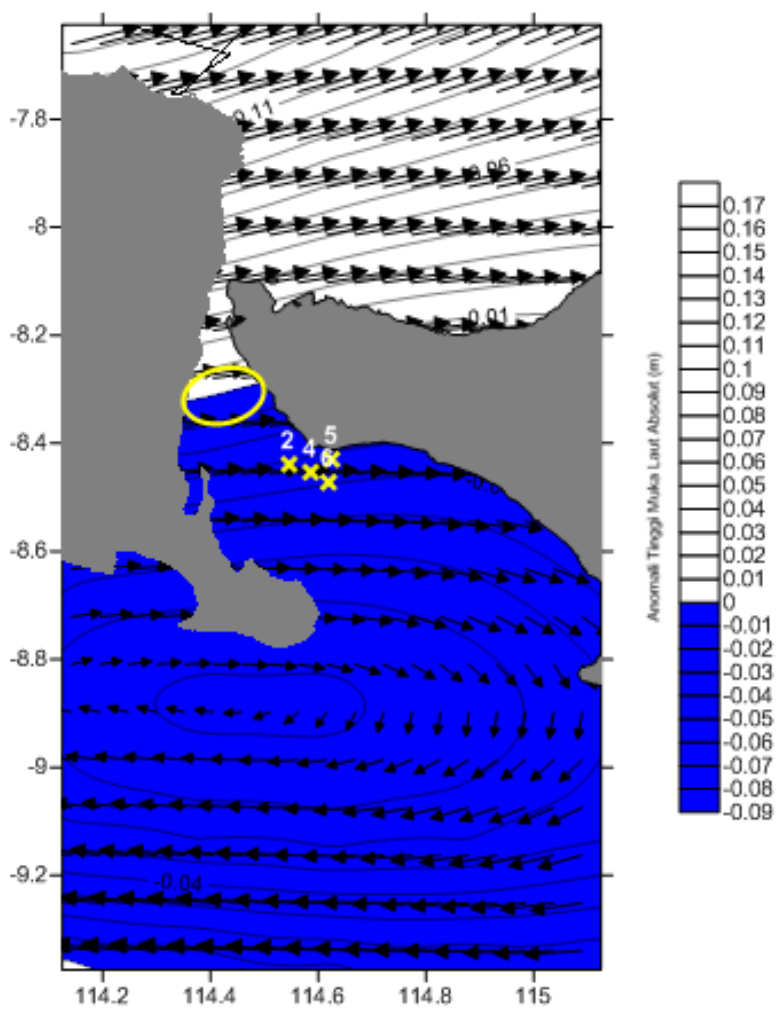

Gambar 13. Overlay Data Arus Geostropik, Anomali Tinggi Muka Laut, dan Data In Situ Tanggal 11 April 2012

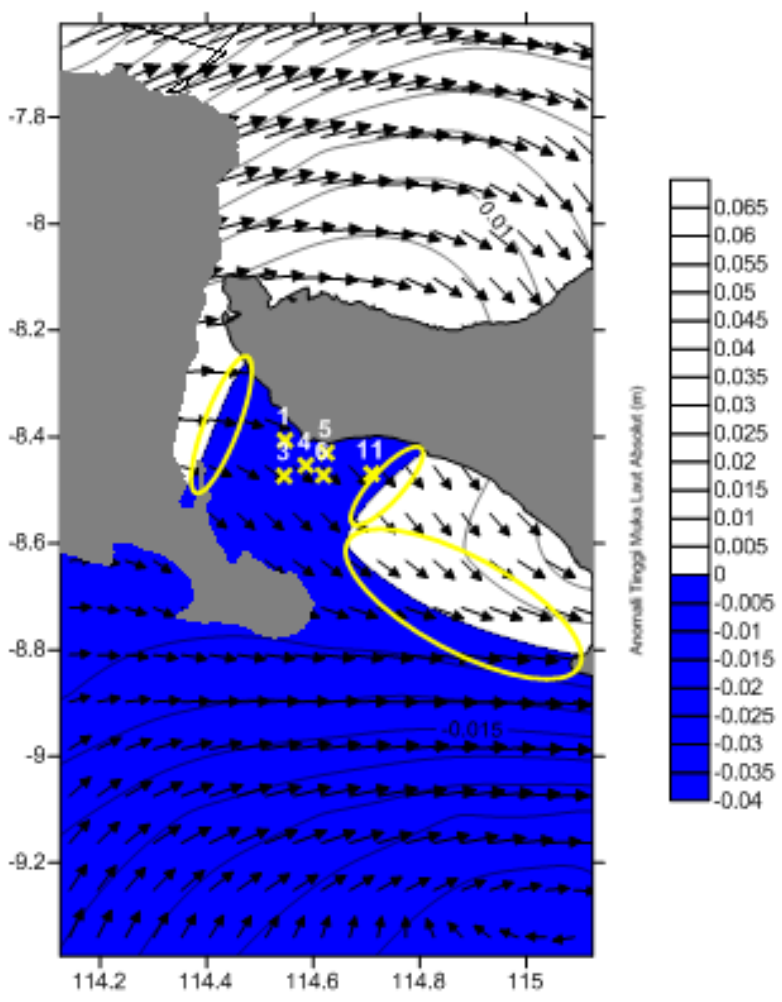

Gambar 14. Overlay Data Arus Geostropik, Anomali Tinggi Muka Laut, dan Data In Situ Tanggal 09 Oktober 2012
Dari hasil overlay data didapatkan bahwa data In Situ berada di daerah upwelling. Hanya titik 11 yang mendekati ZPPI yang telah diidentifikasi menggunakan data altimetri yang ditunjukkan pada lingkaran kuning pada gambar 32. Maka dari itu, perlu dilakukan survei lapangan ke daerah Selat Bali untuk membandingkan potensi sumberdaya ikan dan jenis ikan yang ada di daerah pengambilan data In Situ dan hasil identifikasi ZPPI dari data altimetri untuk mendapatkan hasil yang valid.

\section{KESIMPULAN DAN SARAN}

\section{Kesimpulan}

Kesimpulan dari penelitian ini yaitu:

a. Tinggi muka laut pada Tanggal 11 April 2012 mempunyai nilai tinggi minimum $0,852 \mathrm{~m}$ dan tinggi maksimum 1,094 $\mathrm{m}$ sedangkan tinggi muka laut pada Tanggal 09 Oktober 2012 mempunyai nilai tinggi minimum 0,737 $\mathrm{m}$ dan tinggi maksimum $0,84 \mathrm{~m}$. Untuk anomali tinggi muka laut pada Tanggal 11 April 2012 mempunyai nilai tinggi minimum $0,082 \mathrm{~m}$ dan tinggi maksimum 0,160 $\mathrm{m}$ sedangkan Anomali tinggi muka laut pada Tanggal 09 Oktober 2012 mempunyai nilai tinggi minimum $-0,038 \mathrm{~m}$ dan tinggi maksimum $0,065 \mathrm{~m}$

b. Kecepatan arus geostropik Tanggal 11 April 2012 memiliki kecepatan minimum 0,001 $\mathrm{m} / \mathrm{s}$ dan kecepatan maksimum $1,122 \mathrm{~m} / \mathrm{s}$ sedangkan Kecepatan arus geostropik Tanggal 09 Oktober 2012 memiliki kecepatan minimum $0,004 \mathrm{~m} / \mathrm{s}$ dan kecepatan maksimum 0,670 m/s.

c. Korelasi antara arus geostropik dan anomali tinggi muka laut pada Tanggal 11 April 2012 mempunyai nilai sebesar 0,66 , sedangkan pada Tanggal 09 Oktober 2012 mempunyai nilai 0,70 . hal ini berarti bahwa hubungan antara arus geostropik dan anomali tinggi muka laut memiliki korelasi kuat.

d. Terdapat pergeseran antara Daerah Penangkapan ikan pada Tanggal 11 April 2012 dan 09 Oktober 2012. Hal ini bisa disebabkan karena tinggi muka laut yang semakin menurun dari bulan April 2012 hingga bulan Oktober 2012. Hanya titik 11 pada data In Situ tanggal 09 Oktober 2012 
yang mendekati ZPPI yang telah diidentifikasi menggunakan data altimetri.

\section{Saran}

a. Perlunya melakukan survei primer di Selat Bali pada daerah yang dianggap sebagai Daerah Penangkapan Ikan.

b. Perlu ditambahkan parameter-parameter lain untuk penentuan ZPPI agar Zona Penangkapan Ikan Lebih akurat

c. Data In Situ yang digunakan disesuaikan dengan daerah yang diidentifikasi sebagai Daerah Penangkapan Ikan menggunakan data altimetri.

d. Perlu dilakukan pengamatan letak ZPPI secara berkala tiap tahunnya sehingga nantinya ZPPI tersebut dapat diprediksi keberadaannya.

\section{DAFTAR PUSTAKA}

Anonim. __. Pengembangan dan Penerapan Informasi Spasial dan Temporal Daerah Penangkapan Ikan Berdasarkan Data Penginderaan Jauh. Jakarta

Anonim. 2013. Musim Pancaroba di Indonesia,<URL: http://www.balitbang.jatimprov.go.id/beri ta/detail/berita/443>. Dikunjungi pada Tanggal 6 Juni 2016, jam 09.00

Anonim. 2016. Tim Peneliti Penginderaan Jauh Kelautan,<URL:http://www.bpol.litbang.kk p.go.

id/ocean-remote-sensing>. Dikunjungi pada Tanggal 8 Juni 2016, jam 10.40

Arianto, Bagus Yuli dkk. 2014. Analisis Hubungan Produktivitas Ikan Lemuru dengan Suhu Permukaan Laut dan Klorofil-a Menggunakan Citra Satelit Aqua Modis
(Studi Kasus: Selat Bali). Semarang: Program Studi Teknik Geodesi UNDIP. 3: 158-168

Bachrin, Nidayanti. 2008. Analisis Daerah Potensi Penangkapan Ikan di Perairan Pangkep. Makassar: Universitas Hasanuddin

Barwana, I Gede Pasek Z., Sari, T. Ersti Y., dan Usman. 2014. Effect of Enviromental Parameters to Purse Seine, Catches in Bali Strait. Riau: Fakultas Perikanan dan Kelautan Universitas Riau

Insanu, Radik K., Handayani, Hepi H., Sukojo, Bangun M. 2013. Analisis Pemetaan Zona Penangkapan Ikan (Fishing Ground) dengan Menggunakan Citra Satelit Terra Modis dan Parameter Oseanografi. Surabaya: Teknik Geomatika FTSP-ITS

Marpaung, Sartono dan Prayogo, Teguh. 2014. Analisis Arus Geostropik Permukaan Laut Berdasarkan Data Satelit Altimetri. Seminar Nasional Penginderaan Jauh.

Nilamsuri, Rachma. 2010. Identifikasi Daerah Penangkapan Ikan Dengan Menggunakan Metode Kombinasi Citra Satelit Dan Pemodelan Numerik. Bandung: Institut Teknologi Bandung

Nontji, Anugerah. 2002. Laut Nusantara. Jakarta.

Realiano, B dkk. __. Pola Spasial dan Temporal Kesuburan Perairan Permukaan Laut di Indonesia.Bali: Balai Riset dan Observasi Kelautan

Rosmorduc, V dkk. 2011. Radar Altimetry Tutorial. CLS

Stewart, Robert H. 2008. Introduction To Physical Oceanography. Texas: Texas A\&M University

Wika, Nani Frea. 2014. Satelit Altimetri,<URL: https://naninewfreawika.wordpress.com $/ 2$ 014/03/05/satelit-altimetri>. Dikunjungi pada Tanggal 9 Juni 2016, jam 06.54. 